\title{
BÜLOW, Anna E. and Jess Ahmon. Preparing collections for digitization. London: Facet Publishing. 2011.
}

\section{4 pages. ISBN-978 185604711 1. $£ 44.95$}

Much has been written about digitisation over the past couple of decades, but it has tended to concentrate more on the digital outputs than the physical inputs the items being digitised. In terms of digitisation practices, there is significant discussion in the literature on the resolution and format of digital resources, the metadata we need to accompany them, the ways we can best provide access to them and, increasingly, on how we are going to preserve them. In terms of digitisation policies and strategies, we can trace important debates about quality requirements ("highest possible" vs. "fit for purpose") and appropriate "business models" for creating and sustaining digital content. There is also a recent trend towards more pragmatic approaches to digitisation - in recognition that one size will not fit all collections, institutions or budgets. Although best practice guides are still being produced (the current US Federal Agencies Digitization Guidelines Initiative being particularly noteworthy), those of us who are tasked with managing digitisation projects or programmes are typically developing in-house workflows and guidelines informed by a number of different sources and tailored to meet our local requirements and constraints.

Published digitisation overviews or guidelines will often refer to the challenges of digitising certain materials and the need for careful handling and conservation support, but they seldom go into very much detail. This is because they are typically written by or for digitisation staff, rather than by collection managers or conservation/preservation staff. There are some pockets of support (such as those within the NEDCC's Preservation Leaflet series or the training provided by the British Library Preservation Advisory Centre), but good advice in this area is scarce and Bülow and Ahmon are right to point to this as a gap in the literature. Their book addresses this gap well. It looks at the whole process of digitisation including competent chapters on digital images and imaging technologies - but its particular strength and value lies in the chapters covering collection assessment, preparation and handling. Another key difference with this book is its intended audience. Most books on digitisation are aimed at those managing projects (like this reviewer), but Bülow and Ahmon's work is primarily aimed at "collection managers" - those responsible for managing or preserving physical collections.

Perhaps because those managing physical collections are not universally enthusiastic about digitisation, the book begins by making the case for digitisation. This is generally well presented. Bülow and Ahmon argue that digitisation, handled correctly, can be a useful way of managing the tension between preservation and access. And in tune with current digitisation literature, they also argue that pragmatic and risk-managed approaches are necessary. Such approaches clearly inform the more practical chapters that follow.

For collection managers new to digitisation, the whole book is likely to be of interest, and it is written in a clear and accessible manner well-suited to such an audience. But for those who are more familiar with digitisation, the chapters on surveying collections for digitisation (Chapter 5) and preparation of documents 
(Chapters 7 and 8) will be of special interest and value. Most who have managed digitisation projects will have encountered some of the issues described in these chapters, where seemingly small items such as staples can have a major impact on digitisation workflows and the quality of the digital outputs. Some, like this reviewer, will have had to call in conservators or collection managers to advise on problems during a project, which can be stressful experience for all involved, especially where there are tight deadlines to be met or if damage has occurred. Anyone who has experienced this - or wishes to avoid it - will welcome the clear and practical advice provided in this book.

What this book demonstrates is the importance of developing a strong partnership and mutual understanding between those who are responsible for the digital inputs (the collection managers) and those responsible for the digital outputs (the digitisation professionals). Both groups will be well served by this book.

\title{
References
}

British Library (2011) Preservation Advisory Centre. URL: http://www.bl.uk/blpac/ [accessed 31.5.11].

Federal Agencies Digitization Guidelines Initiative (2011) Federal Agencies Digitization Guidelines Initiative. URL: http://www.digitizationguidelines.gov/ [accessed 31.5.11].

North East Document Conservation Center (2011) Preservation Leaflets. URL: http://www.nedcc.org/resources/leaflets.list.php [accessed 31.5.11].

\author{
Grant Young \\ Digitisation and Digital Preservation Manager \\ Cambridge University Library \\ gy219@cam.ac.uk
}

\section{Open access and copyright}

Library and Information Research is an open access journal. A freely available copy of this paper may be downloaded from the journal's website: http://www.cilipjournals.org.uk/lir

Copyright and associated moral rights in works published in Library and Information Research are retained by the author(s) but this paper may be used freely, with proper attribution, in educational and other non-commercial settings. 